\title{
Game development as a pedagogical mechanism: a report on an experiment in public schools aimed at sustainability and the protection of the environment.
}

\author{
Sara das Mercês Silva, Fabíla Pantoja O. Araujo ${ }^{1}$, Saulo W. da Silva Costa ${ }^{3}$, Yomara Pinheiro Pires ${ }^{3}$, \\ Marcos C. da Rocha Seruffo ${ }^{2}$, Josivaldo S. Araujo ${ }^{1}$, Hieda Adriana N. Silva ${ }^{3}$ \\ (1.Instituto de Ciências Exatas e Naturais (ICEN); 2. Instituto de Tecnologia (ITEC) \\ Universidade Federal do Pará (UFPA) Rua Augusto Corrêa, 01 - 66075-110 - Belém - PA - \\ Brasil; 3. Campus Castanhal - Universidade Federal do Pará (UFPA) Av. dos Universitários - \\ 68746-360 Castanhal-PA-Brasil)
}

\begin{abstract}
Educational games have been designed in this study with the aim of arousing an interest in environmental education among 5th grade student, which involve making sustainable use of the river that flows through the municipality of Inhangapi, located in the North-East of Para State'. The students' gain in knowledge regarding the subjects covered in class was assessed at the end of the students' game activities that involved the subjects taught. The results showed that the use of game construction contributed to the teaching and learning process with regard to the concepts of Computing and environmental education because almost $60 \%$ of the students correctly applied what they had been taught about game construction.
\end{abstract}

\section{Introduction}

The teaching of Computing, in the early school years, is a means of including people, in the current context of New Digital Technologies of Information and Communication (NDTIC) in their childhood.

The students are already able to understand algorithms in their childhood, as long as concepts are taught in a correct way that is appropriate the students ages. In addition, in his research he explores how far learning computer programming logic is interesting and fun for children and can arouse an interest in students as well as encouraging them to continue learning. This is evidence that programming logic (PL) can assist in the learning of other subjects taught at school (Mittermeir, 2013).

${ }^{1}$ Sara das Mercês Silva, Bachelor of Computer Engineering, Federal University of Pará, Institute of Exact Sciences and Natural; research area/interests: digital inclusion, social media, women's empowerment. E-mail: maru.merces18@gmail.com.

${ }^{1}$ Fabiola Pantoja Oliveira Araújo, Master in Informatics, PhD in Electrical Engineering, Adjunct Professor at Federal University of Pará, Institute of Exact Sciences and Natural; research area/interests: Computational Intelligence, Speech Synthesis, Databases, Informatics in Education. E-mail: fpoliveira@ufpa.br.

${ }^{3}$ Yomara Pinheiro Pires, Master and PhD in Electrical Engineering, Associate Professor at Federal University of Pará; research area/interests: Informatics in Education, Affective Computing, Artificial Intelligence. E-mail: yomara@ufpa.br. ${ }^{2}$ Marcos Cesar da Rocha Seruffo, specialist in Computer Systems Technical Support, Master in

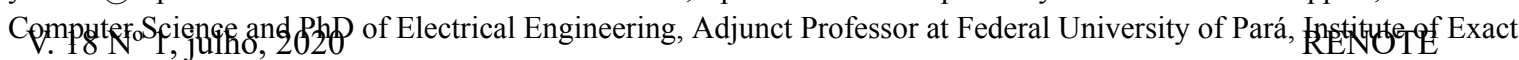
DOI: 
Sciences and Natural; research area/interests: Informatics in Education, User Experience, Social Technologies. E-mail: seruffo@ufpa.br.

'Josivaldo Souza Araújo, Master and PhD in Eletrical Engeneering, Associate Professor at Federal University of Pará, Institute of Exact Sciences and Natural; research area/interests: High Performance Computing, Parallel Processing, Distributed Systems and Computer Networks. E-mail: josivaldo@ufpa.br

${ }^{3}$ Hieda Adriana N. Silva, Master in Computer Science and PhD in Information and Communication Technology (ICT) - La Sapienza, University of Rome, Adjunct Professor at Federal University of Pará; research area/interests: Machine Learning, particularly Neural Networks, Deep Learning and Time-Series Analysis. E-mail: hieda@ufpa.br.

The teaching of algorithms and computational thinking to children and teenagers has already been applied in research, such as in (Garlet et al. 2016, Williams et al. 2015, Farias et al. 2018). The work of Garlet (2016), underlines the importance of teaching programming logic in primary education, as a means of preparing students for higher education. As regards the use of games, as a tool to help the teaching of logic, Williams et al. (2015) claim that its use can help to familiarize students with the fundamentals of algorithms. In Farias et al. (2018) explain a gamification scheme for programming logic, which increases the student's commitment.

The opportunities provided by advances in Computing, have been reflecting the way that people, especially children and young people, interact with the world, and influence them in the way knowledge is derived. It should be realized that the inclusion of technologies in the educational world, leads to positive changes in teaching and learning, and also helps attenuating the discrepancies between different educational environments (Alves et al., 2018).

In view of this, the objectives of this study involved employing basic concepts of programming logic to the development of educational games. They are also designed to teach concepts of environmental education and sustainability to children and teenagers from the town of Inhangapi, located in a riverside region of the Amazon, in the North-East of Pará. On the basis of data made available by the Information System of Social Indicators in Pará State, it is known that only three schools in the municipal education network, where the work was carried out, have a computer laboratory, and of these, only one has access to the Internet.

A Scratch tool was used to encourage students to become interested in programming and the environment, and to design an educational game which could be used as a pedagogical resource to assist in the teaching and learning of students in the 5th grade of elementary school. The game was designed to replicate the act of removing trash from the river in the municipality and thus followed closely the pedagogical concepts of teaching children in terms of their real circumstances and addressing issues related to environmental education.

The school is located a few meters from the river that flows through the municipality and gives it its name. As it is a small town with little infrastructure, the activities such as those carried out in this work, were also aimed at fostering local development. As well as teaching programming logic, socio-environmental concepts were defined, since the main purpose of the game development was to contribute to the teaching of environmental education and the preservation of the local river. At the end of the classes, the students modified the design and logic of the base game, that was created in the classroom, by applying the content of the algorithm taught in the class. In addition to this activity, students answered a post-project questionnaire to assess whether they were able to assimilate all the covered concepts.

This paper is structured as follows: in Section 2 there is an examination of related works. Section 3 describes the methodology used in this work and the details of the game used as a reference (base game). In Section 4 there is an analysis of the results of the structured questionnaires and the evaluation activity performed in the classroom. Finally, Section 5, concludes the study with some final considerations.

\section{Related works}

V. $18 \mathrm{~N}^{\mathrm{o}} 1$, julho, 2020

DOI: 
Several research studies have been conducted that support the use of educational games as a pedagogical tool, that can assist in the teaching-learning process, and the teaching of programming concepts inside the classroom.

An educational electronic game to help students learn orthography has already been designed (Pires et al., 2018). The results achieved suggest that the game is able to help in the learning process, 12 users confirmed this result, when they evaluated the game. In Guerra et al. (2018) shows how games can be used to assist in improving children's literacy in public schools. The authors have been working on tests with children in this area since 2015, and claim that in this period they have been able to improve the level of literacy of about 400 children.

In their work, Mesquita et al. (2018) describes a platform that is established to allow the teachers and students themselves to design games in a simple way, and adapt the concepts of the games to the pedagogical purposes of each subject and teacher. The teachers and students used previously developed games and then created their own, after which they answered a quiz, which had been made available by the authors.

As regards children building digital games within the educational environment as a school activity, Cruz et al.(2012) shows an experience of creating games in a public school. The authors claim that the students were able to carry out the activity themselves and become interested in game development. Garlet (2016) shows the importance of teaching programming logic in primary education, to prepare students for higher education. As for the use of games as a tool to help the teaching of logic, Williams et al. (2015) reports that its use has helped to familiarize students with algorithm fundamentals.

There are similarities between the cited papers and this study: for example the way the use and construction of games can assist in a particular subject and bring people closer to computing. Some authors have also used questionnaires to evaluate their results, but in this work, as well as being asked to complete a quiz, the students were evaluated through a practical game development activity. This contrasts with the related works which failed to describe how digital games were created and inspired by the daily lives of children and only focused on environmental education.

\section{Methodology}

This study describes an experiment that was undertaken at the Aristides Santa Rosa School, (as mentioned above), which sought to apply game development to teaching algorithm concepts and the learning of environmental education. Two classes of elementary school took part in this work, and attended practical and theoretical classes, making a total of 20 students with ages ranging between 9 and 13.y. The legal guardians of the students, who took part in the activities described here, signed the Free and Informed Consent Form (ICF).

\subsection{Game Development Methodology}

The lessons took place in the school's computer laboratory, twice a week for a month. The initial lessons focused on the basic concepts of computing. In the first lesson, topics of programming logic were taught, with the aid of multimedia resources (slides, images, and the Internet) and the practical dynamics of creating algorithms for the daily lives of children, these included: algorithms for baking a cake, and brushing one's teeth among other tasks. It also involved explaining to students, playfully, what logical steps should be taken and how an algorithm works.

In the following lessons, groups of 3 students. It was at this time that, the construction of the game began. When the children were already assembled together in groups, the necessary characters included (e.g. garbage, river, fish, a boy), and the programming developed, the teaching began of themes related to the preservation of the environment and sustainable use of V. $18 \mathrm{~N}^{\mathrm{o}} 1$, julho, 2020 RENOTE

DOI: 
the local river. The construction and the features of the base game were used for this: when the boy's character was added, the attention of the students was drawn to their role with regard to the preservation and sustainable use of the Amazon forest and its resources.

When the river was included as a backdrop, its importance for the children and the entire local population was discussed, together with the inclusion of fish species, the Amazon flora and fauna and their importance to the forest and the people themselves. There was also a debate about how flora and fauna should be treated in a sustainable way. In addition, the problem of waste was addressed and the harm caused by this pollution to the environment, as well as to humans and examples were given of the suitable disposal of recyclable solid waste. This meant that the children learned not only about computing concepts, but were also taught in a playful and targeted way about subjects such as sustainability and environmental protection, issues which form an essential part of environmental education.

In determining whether students really understood and absorbed the concepts of algorithms and environmental education, there was an assessment of how the students first followed the teachers' instructions and created their base game and, in a second stage, modified their logic and design, by putting into practice what they had learned in previous lessons. It was decided to divide the students into groups and carry out activities that involved games, to assist in the construction of learning, based on a post-constructivist approach, which is based on the assumption that everyone can learn together and that group learning is very important because it is a social act (Grossi, 1990).

\subsection{Game building}

It was decided to use the Scratch software for the lessons because it is a tool that is free tool, available in Portuguese and designed for the age group of the students who took part in the research. In their research study, Rezende et al. (2018) states that the use of Scratch assists in the learning of algorithm concepts.

In visual terms, the game comprises a background image, two fishes, a boy and some trash bags (Figure 1). During the game, the boy gives instructions using text boxes. Simple algorithms are employed to take account of the age and knowledge level of students (which can be inferred from a structured questionnaire before classes).

The main objective of the game is to remove the trash from the river before the fish touch the garbage bags. If this happens the fish will disappear (die). By clicking on the right-hand button of the mouse above the bags, the player can remove the trash from the river. The game ends when all the trash bags have been removed or all the fish have died. The characters, background images and programming blocks, used to build the game, are available in Scratch, but some groups use images from the Internet. The programming logic of the characters was developed separately and this helped the children to understand the logic of each character.

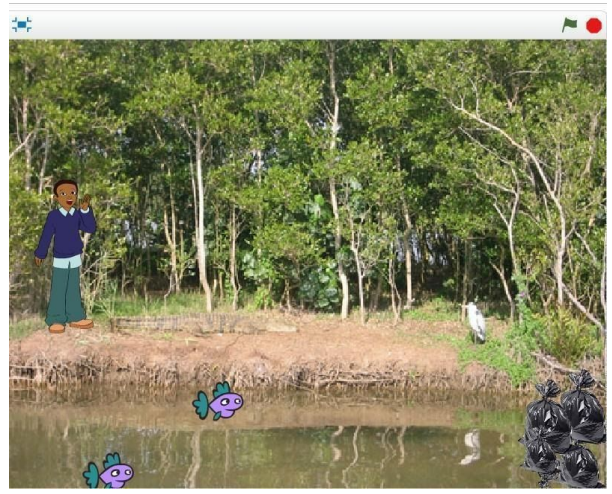

V. $18 \mathrm{~N}^{\mathrm{o}}$ 1, julho, 2020 Figure 1. Visual Design of the base game. DOI: 


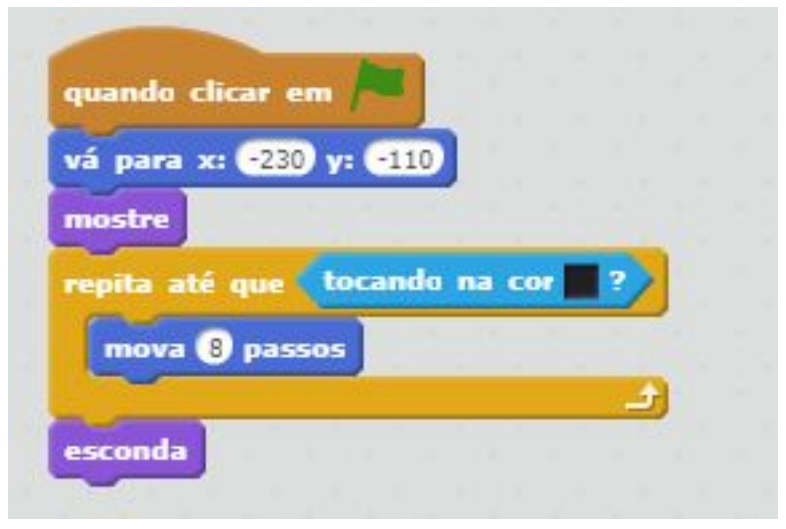

Figure 2. Programming logic of the fish character.

The action performed by the fish in the game were: a) to swim towards the trash bags and b) to disappear if they touched them (Figure 2). The orange block was responsible for starting the game and the fish should move and perform programmed actions.

The blue block showed the direction that the fish should follow and the purple (written "show") kept the fish visible as long as it did not touch the black shade that represents the trash bags. The yellow block simulated the movement of the fish, and the blue block, inside the yellow block, was responsible for showing the movement and speed of the fish. Lastly the purple block (written "hide") made the fish invisible, when it touched the trash bags. The action of the boy was to give instructions to the player using text boxes.

The first block (orange), was responsible for starting the game and the boy carried out his activities; the first block (purple) changed the boys position. The second and the third blocks were about the instructions that the boy gave to the players and the time when these instructions were available (Figure 3).

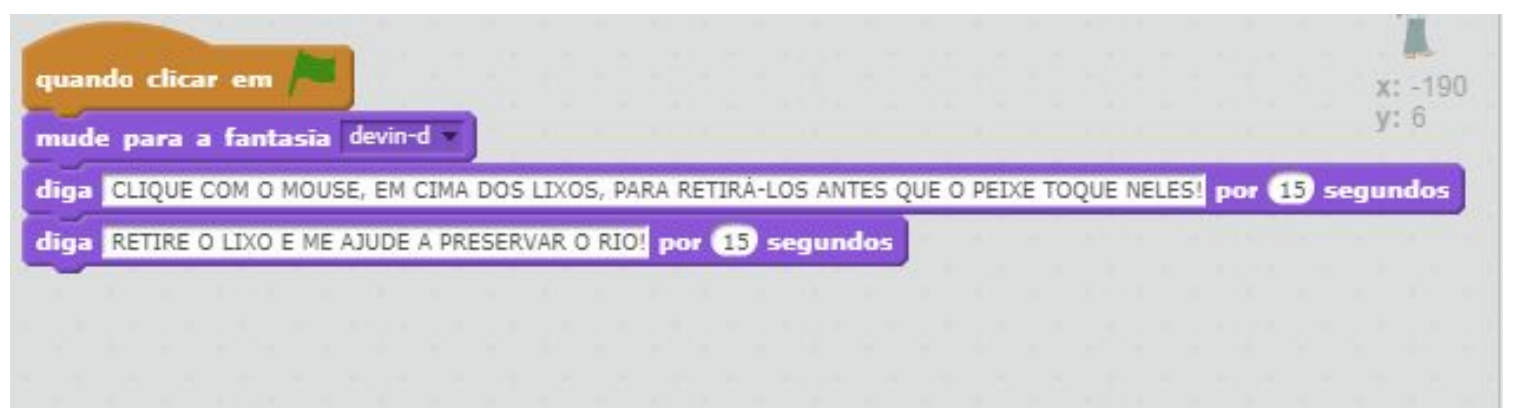

Figure 3. Programming logic of the boy character

The functions of the garbage character in the game, were: to disappear when a player touched him with the mouse button. The first block (orange) started the game, the purple block (written "show") was responsible for making the trash bags visible when the game started. The orange block and the lilac block made the garbage disappear (Figure 4). 


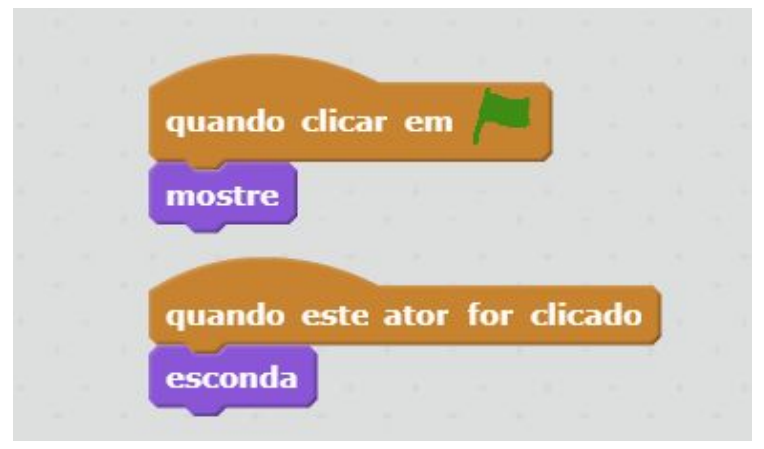

Figure 4. Programming logic of the trash character

\section{Results}

The results were evaluated in two ways, through two structured questionnaires: the first applied before the beginning of the classes on programming logic and the second after game development. The questionnaires included multiple choice and open-ended questions.

Table 1 shows the main questions contained in the questionnaires and the results of the students' responses are highlighted. The second type of assessment was based on a classroom activity: With the aid of the programming logic and environmental education learned in the class, the students made adjustments to the base game, and developed new games. This kind of activity, alters the way an existing game is programmed and is known as "remixing". Mattar (2010) states that the practice of remixing is widely used in Scratch projects.

\begin{tabular}{|l|l|l|}
\hline Question & First Questionnaire & Second Questionnaire \\
\hline $\begin{array}{l}\text { Most widely used information } \\
\text { medium? }\end{array}$ & $\begin{array}{l}\text { Television (75\%) } \\
\text { The Internet (20\%) } \\
\text { Radio (5\%) }\end{array}$ & X \\
\hline $\begin{array}{l}\text { Do you know the algorithm? } \\
\text { If so, what is it? }\end{array}$ & $\begin{array}{l}\text { Everyone said they didn't } \\
\text { know it }\end{array}$ & $84 \%$ managed to answer \\
\hline Define sustainability & $\begin{array}{l}\text { Everyone said they didn't } \\
\text { know the meaning of this } \\
\text { word }\end{array}$ & $35 \%$ managed to answer \\
\hline $\begin{array}{l}\text { Would you like to learn / did } \\
\text { you enjoy learning how to } \\
\text { build a game }\end{array}$ & Everyone said yes & Everyone said yes \\
\hline
\end{tabular}

Tabela 1. Results of the structured questionnaire

\subsection{Results of the structured questionnaires}

The purpose of the first questionnaire (Table 1) is to obtain knowledge about the student's age, the most widely used information medium and their relationship with the environment. Sixty five percent of the students are male, $70 \%$ are in the $8-10$ age group and the most widely used information medium was television (75\%), but $83 \%$ of the children stated that they would like to have more access to the Internet. With regard to the river in the municipality, $100 \%$ of the students used the river and its resources everyday. Seventy nine percent of the students stated that they are aware of garbage in the river, $100 \%$ of the children did not know what sustainability means and were also unaware of the damage caused by

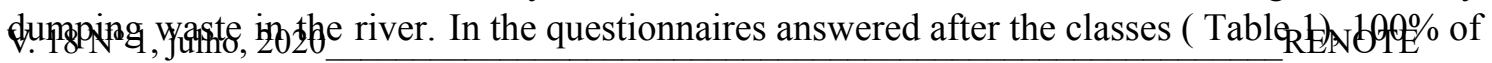
DOI: 
the children correctly answered questions about the consequences of polluting the river, and the need to protect the environment and $35 \%$ when asked what is sustainability, were able to answer correctly.

The students showed very little or knowledge of programming logic in the results of the first questionnaire and when developing their first games. After the classes, $84 \%$ of the children answered the questions in the second questionnaire about programming logic correctly, and showed an interest in learning more about the logic algorithm and the game that had been created. In the beginning, $91 \%$ of the students stated that they did not know what the word "application" meant, but on the basis of the questionnaire data, after the classes, $82 \%$ correctly answered questions involving application concepts. Showing that programming logic can and should be taught to children as stated Garlet (2016) show the importance of teaching programming logic in primary education.

\subsection{Evaluation of activities involving changes to the base-game}

When the students had finished designing the base-game and already learned the concepts of programming logic and sustainable practices their groups were asked to change the design and logic of the base game. This activity took place under the supervision of the teacher. The groups were evaluated in accordance with the types of changes they were able to introduce to the base game, while keeping the same logic they had been taught. They were also assessed in terms of which groups only changed the game-base design and adopted a different logic to that used in the game-base.

It can be stated that all the groups were able to complete the activity entirely or in part, $45 \%$ of the groups only changed the base-game design and $55 \%$ of the groups changed the design and the programming logic of the base-game, by issuing the logic commands for different characters, and either adapting them or changing some of the commands within the algorithm of each character. This shows that the use of games can be a tool for teaching how to speak Pires, (2018) designed an educational electronic game to assist students in learning orthography. The results achieved suggest that the game is able to help in the learning process.

It should be noted that all the groups made the protection of the environment and sustainability the focal point of the new games, and adopted the concepts they had learned in the classroom about environmental education. Figure 6 illustrates the new game design of a group which kept some of the some characters (trash and fish) from the base game and applied the logic commands to the characters in a different way, as well as adding a new character, the diver.

In the base game, the fish moves towards the trash and the character of the boy gives the instructions. In Figure 6, the diver moves and gives instructions. This means that, despite being based on the commands of the fish and trash in the base game, the diver's programming logic (Figure 5) differs in some respects from the boy and fish characters in that the diver is programmed to display information to the player throughout the game and not just for a short time, as in the case of the boy character. In addition, unlike the fish that vanishes when it comes into contact with the trash, the diver does not disappear.

\section{Conclusion}

The results of the questionnaires showed that, despite enjoying nature and its benefits, the students were unaware of the need to protect the environment. After the classes, there were discussions on sustainability and environmental protection with the aid of the computer for a targeted activity (building the game), and this enabled them to acquire more knowledge about the importance of preserving the river and its resources. The activity to change the logic and design V. $18 \mathrm{~N}^{\mathrm{o}} 1$, julho, 2020 DOI: RENOTE 
of the base game, showed that $55 \%$ of the students issued the logic commands that were taught through the construction of the game. This demonstrated that children are able to learn programming concepts through supervised activities adapted to their age.

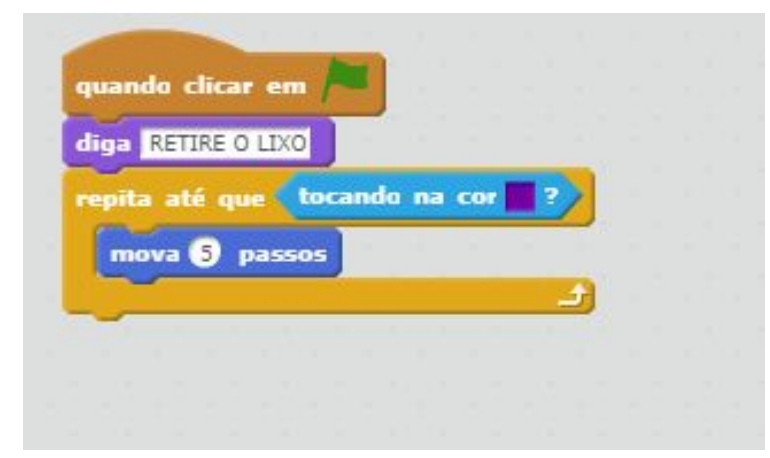

Figure 5. New programming logic.

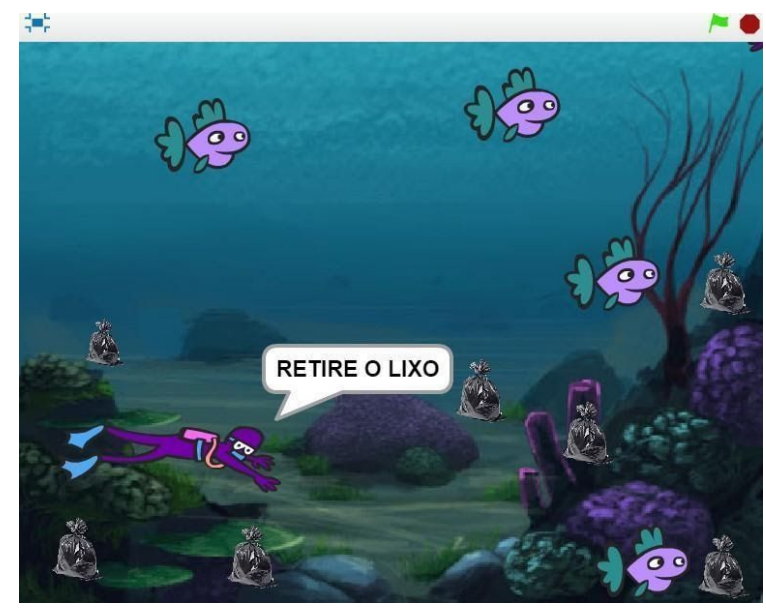

Figure 6. New game design developed by one of the groups.

The use of educational games at school and the New Digital Technologies of Information and Communication are attractive to students and can be to used as a tool to help in the teaching and learning process of computing and other key issues (e.g. sustainability and environmental protection), by providing a very interactive environment. In future work, it is recommended that lessons on programming should continue to be taught in the school, as well as the use of games designed to foster sustainable practices and the protection of the environment in the schools of the town. This is because it is a typical Amazonian region and there is a clear need to arouse an awareness of their socio-environmental responsibilities among the local people, even in their childhood.

\section{Bibliographical References}

ALVES, J.; ALMEIDA, A.; VIEIRA, M.; CARVALHO, A.; LEITE, M. IFQuimical: uma proposta de mediação no processo ensino-aprendizagem de química. In: BRAZILIAN SYMPOSIUM ON COMPUTERS IN EDUCATION (SIMPÓSIO BRASILEIRO DE INFORMÁTICA NA EDUCAÇÃO - SBIE). 2018, Fortaleza. Anais. Fortaleza: Sociedade Brasileira de Computação, 2018, p. 61.

CRUZ, D. M., ALBUQUERQUE, R. M.; AZEVEDO, V. A. Criar e jogar seu próprio jogo: a produção de games na escola. In: ANAIS DO COMPUTER ON THE BEACH, 2012, V. $18 \mathrm{~N}^{\circ} 1$, julho, 2020 RENOTE

DOI: 
Florianópolis. Anais: UNIVALI: Sociedade Brasileira de Computação, 2012, p.117-126.

DE FARIAS, C. M.; AZEVEDO, F. P.; DIAS, J. E. DE J. Uma Abordagem Gamificada para o Ensino de Lógica de Programação: relato de experiência. In: WORKSHOP SOBRE EDUCAÇÃO EM COMPUTAÇÃO (WEI), 2018, Natal. Anais. Natal: Sociedade Brasileira de Computação, 2018, p.1-10.

GARLET, D. Uma proposta para o ensino de programação de computadores na educação básica. Rio Grande do Sul. Santa Maria: Universidade Federal de Santa Maria, Campus de Frederico Westphalen, 2016. Trabalho de Conclusão de Curso.

GROSSI, E. In: Paz e Terra (Ed). Didática da alfabetização. Porto Alegre: Vol. 2. 1997. 200p.

GUERRA, F.; SANTOS, J. A.; SEREY, D.; FIGUEIREDO, J. C. A. z-Reader: a Mobile Game Suite for Improving Children's Reading Skills and Behavior. In: BRAZILIAN SYMPOSIUM ON COMPUTERS IN EDUCATION (SIMPÓSIO BRASILEIRO DE INFORMÁTICA NA EDUCAÇÃO - SBIE). 2018, Fortaleza. Anais. Fortaleza: Sociedade Brasileira de Computação, 2018, p. 565.

MATTAR, J. In: Pearson Prentice Hall (Ed). Games em Educação: como os nativos digitais aprendem. São Paulo: 2010. 181p.

MESQUITA, H. O.; ARANHA, E.; SILVA, T. Uma Abordagem para o Desenvolvimento de Jogos Digitais Educativos no Ensino Básico. In: BRAZILIAN SYMPOSIUM ON COMPUTERS IN EDUCATION (SIMPÓSIO BRASILEIRO DE INFORMÁTICA NA EDUCAÇÃO - SBIE). 2018, Fortaleza. Anais. Fortaleza: Sociedade Brasileira de Computação, 2018, p. 874.

MITTERMEIR, R. Algorithmics for Preschoolers-A Contradiction?. Creative Education. (2013) Vol. 04. 557-562. 10.4236/ce.2013.49081.

PIRES, F. G. DE S.; MICHEL, F.; BERNARDO, J. R. S.; FERREIRA, R. M.; FREITAS, R. O livro do conhecimento: Um jogo de aventura para exercitar a ortografia. In: BRAZILIAN SYMPOSIUM ON COMPUTERS IN EDUCATION (SIMPÓSIO BRASILEIRO DE INFORMÁTICA NA EDUCAÇÃO - SBIE). 2018, Fortaleza. Anais. Fortaleza: Sociedade Brasileira de Computação. 2018, p. 695.

REZENDE, C.; BISPO, E. Comparison between the use of pseudocode and visual programming in programming teaching: An evaluation from scratch tool. In: 13TH IBERIAN CONFERENCE ON INFORMATION SYSTEMS AND TECHNOLOGIES (CISTI), 2013, Spain. Proceedings. Institute of Electrical and Electronics Engineers, 2013.

WILLIAMS, C. et al. Teaching programming concepts to elementary students. In FRONTIERS IN EDUCATION. CONFERENCE (FIE), 2015, USA. Proceedings. Institute of Electrical and Electronics Engineers. 2015. 